\title{
Effects of Vowel Context and Stimulus Length on Test-Retest Nasalance Variability between Children and Adults with Normal Speech
}

\author{
Seunghee $\mathrm{Ha}^{\mathrm{a}}$, Ilsan Shin ${ }^{\mathrm{b}}$ \\ ${ }^{a}$ Division of Speech Pathology and Audiology, Audiology and Speech Pathology Research Institute, Hallym University, Chuncheon, Korea \\ ${ }^{b}$ Graduate Program in Speech Language Pathology, Hallym University, Chuncheon, Korea
}

Correspondence: Seunghee $\mathrm{Ha}, \mathrm{PhD}$ Division of Speech Pathology and Audiology, Audiology and Speech Pathology Research Institute, Hallym University, 1 Hallimdaehak-gil, Chuncheon 24252, Korea

Tel: +82-33-248-2215

Fax: +82-33-256-3420

E-mail: shha@hallym.ac.kr

Received: April 9, 2017

Revised: May 10, 2017

Accepted: May 14, 2017

\begin{abstract}
Objectives: This study aims to investigate whether test-retest nasalance scores are different between children and adults and influenced by vowel context and stimulus length. Methods: The participants were twenty adults and thirty children age 4 to 5 years with normal speech. They repeated each speech stimulus twice after an examiner without headgear reposition. The speech stimuli consisted of 4-, 8-, 16-, and 31-syllable sets and each set was loaded with high, low, and mixed vowels. Absolute differences between the nasalance scores from the first and second recordings were obtained to see the effect of vowel context and stimulus length on variability in nasalance between the groups. Results: Variability in nasalance scores was influenced by vowel context and stimulus length and there was no significant difference between children and adults. There were no significant interactions between the variables. Post hoc tests revealed that nasalance difference scores in the high vowel context were greater than those in the low and the mixed vowel contexts. Also, 4-syllable stimuli showed greater nasalance differences scores than 16- and 31-syllable stimuli. More adults and children exhibited greater than 5 nasalance difference points for the 4-syllable stimulus in the high vowel context. Conclusion: The study suggested that test-retest nasalance variability would become greater as the ratio of the high vowels increases and stimulus length is shorter. For clinical purposes, it is necessary to measure nasalance scores at least twice for the identical speech stimuli.
\end{abstract}

Keywords: Nasalance scores, Vowel context, Stimulus length, Adults, Children
공명 장애의 유무와 심각도를 타당하고 정확하게 평가하기 위해 서는 공명 장애에 대한 임상 경험이 많은 임상가의 청지각적 판단 과 함께 비강 및 구강 내 공명 정도를 정량화할 수 있는 음향학적 평가가 이루어져야 한다(Cho \& Ha, 2015; Kuehn \& Moller, 2000). 비음측정기(nasometer)는 대표적인 공명 장애를 평가하는 음향학 적 도구로서 비강과 구강의 전체 음향학적 에너지에서 비강의 음향 학적 에너지의 상대적인 비율을 나타내는 비음치(nasalance scores) 를 제시한다. 비음치를 바탕으로 임상가의 주관적인 청지각적 판단 을 보완할 수 있다. 비음측정기가 공명 장애 정도를 객관적으로 수 량화하여 평가할 수 있는 장점으로 인해 현재 임상 현장에서 가장
보편적으로 사용되고 있지만, 비음치의 검사-재검사 신뢰도에 대 한 문제가 지속적으로 제기되고 있다(Lewis, Watterson, \& Blanton, 2008; Litzaw \& Dalston, 1992; Seaver, Dalston, Leeper, \& Adams, 1991; Watterson \& Lewis, 2006). 즉 동일한 검사어를 화자가 연속적으로 말해 비음치를 여러 번 측정할 때 그 수치가 완전하게 동일하지 않고 다른 수치가 나올 수 있다는 것이다. 이러한 점은 임 상 현장에서 큰 문제가 될 수 있는데, 특히 연인두 기제상의 문제로 실시된 2차 입천장 교정술의 효과를 평가하거나 언어치료 전-후로 공명상의 변화를 측정할 때 문제가 될 수 있다. 수술과 언어치료 전-후에 측정한 비음치의 차이가 수술과 언어치료로 인한 공명상 
의 변화가 아닌 단순한 비음치 측정상의 변이성으로 인해 생긴 차 이일 수 있기 때문에 수술과 언어치료의 효과를 과대평가할 수 있 는 위험이 있다.

검사-재검사의 비음치가 달라지는 주요한 원인으로 화자의 수행 력상의 변화(subject performance variability)와 비음측정기 헤드 기어의 위치 변경이 주로 논의되고 있다(Watterson, Lewis, \& Brancamp, 2005; Watterson \& Lewis, 2006). Seaver 등(1991)은 화자의 수행력과 관련된 비음치의 변이성을 처음으로 보고하였는데, 40 명 의 성인을 대상으로 헤드기어의 위치 변경 없이 Zoo passage를 세 번 연속으로 읽게 한 후 비음치를 측정하였다. 연구결과, 성인 중 $97 \%$ 가 3점 이내의 서로 다른 비음치를 보였으며 나머지 3\%는 3점 이상의 비음치 차이를 보였다. Litzaw와 Dalston (1992)에서도 비슷 한 연구결과가 나와, 이후 일반적으로 헤드기어를 변경하지 않은 상태에서는 3 점 정도의 검사-재검사 비음치 차이는 정상적인 편차 (typical variation)로 받아들여졌다(Watterson \& Lewis, 2006). 또 한 Watterson 등(2005)은 화자의 수행력과 함께 헤드기어의 재착 용이 비음치의 변이성에 어느 정도 영향을 미치는지 살펴보았다. 연구결과, 헤드기어를 변경한 후에 측정한 비음치의 검사-재검사 차이가 더 크고, 헤드기어 재착용과 화자의 수행력상의 변화를 모 두 고려하면 5점을 일반적인 비음치의 검사-재검사 편차로 설명할 수 있다고 제안하였다.

화자의 수행력상의 변화로 인해 생기는 검사-재검사 비음치 변이 성은 화자가 검사어를 말할 때 청자가 지각할 수 있는 음운 수준 (phonemic level)에서는 차이가 없으나 미묘하게 조음의 움직임이 달라져 비강과 구강 내 음향학적 에너지 비율이 달라지는 것을 의 미한다. 이러한 화자의 수행력상의 변화는 성인보다는 아동에게서 더 크게 관찰될 수 있다. 일부 아동은 말을 습득하는 과정 중에 있 기 때문에 음운적인 면에서는 일관성 있게 정확하게 말소리를 산 출할 수 있는 발달 단계에 도달했으나, 조음 기관의 움직임의 범위 와 타이밍 면에서 성인과 비교해서 덜 안정적일 수 있다(Chermak \& Schneiderman, 1985; Kent, 1992). 따라서 그 결과로 나타나는 비 강과 구강의 상대적인 음향학적 에너지와 관련된 음성적인 면에서 는 개인 내 편차를 보일 수 있기 때문에 성인보다 더 변이적인 비음 치를 보일 가능성이 있다. 호주 일반 아동을 대상으로 비음치를 보 고한 Van Doorn과 Purcell (1998)은 이러한 아동의 조음 기관, 특 히 연인두 폐쇄와 개방의 타이밍상의 불안정성을 토대로 아동이 성 인보다 더 변이적인 비음치를 보일 거라고 추측하였다. 하지만 연구 자들은 성인과 아동의 자료를 직접적으로 비교하지는 않았으며, 현 재까지 비음치의 변이성을 살펴본 연구는 모두 성인을 대상으로 이 루어져 성인과 비교해 아동의 수행력을 살펴본 연구는 아직 이루
어지지 않았다.

또한 비음치의 검사-재검사 차이는 검사어 유형에 따라서도 달 라질 수 있다. 비음치의 영어권 연구에서는 주로 세 가지 유형의 검 사어를 사용하는데, 비자음이 포함되지 않은 Zoo passage와 비자 음과 구강자음이 모두 포함된 Rainbow passage, 비자음으로만 구 성된 문장을 사용한다. 비음치의 변이성을 보고한 연구에서는 Zoo passage보다는 Rainbow passage나 비자음으로만 구성된 문장에 서 보다 많은 대상자들이 3점 이상의 검사-재검사 비음치 차이를 보였다(Seaver et al., 1991; Van Doorn \& Purcell, 1998). 말할 때 지 속적인 연인두 폐쇄만이 필요한 Zoo passage와 비교해 Rainbow passage와 비자음 문장은 연속적으로 나오는 일련의 구강자음이 나 모음과 비자음 산출을 위해 반복적인 연인두 폐쇄와 개방이 필 요하다. 따라서 동일한 검사어 이지만 산출할 때마다 연인두 폐쇄 와 개방의 타이밍과 협응의 정도가 미묘하게 달라질 수 있다. 그 결 과로 비강과 구강 내 음향학적 에너지도 약간씩 달라져 구강자음 이나 모음과 비자음이 혼합된 문장이 더 큰 비음치 변이성을 보일 수 있다고 추론해 볼수 있다(Van Doorn \& Purcell, 1998).

비음치의 검사-재검사 신뢰도를 살펴본 국내 연구에는 $\mathrm{Kim}$, Sim과 Choi (2000)가 있다. Kim 등(2000) 연구에서는 모음환경과 검사어의 길이에 따라 비음치 점수를 살펴보면서, 피어슨 상관분석 을 토대로 비음치의 검사-재검사 신뢰도를 살펴보았다. 연구결과, 고모음 환경과 비음과 후설음 문장에서 피어슨 상관계수가 상대적 으로 더 높았으며, 검사어의 길이가 길수록 검사-재검사 신뢰도가 높았다. Kim 등(2000)은 검사어의 음운환경과 길이에 따라 신뢰도 가 통계적으로 유의한 차이를 보이는지 살펴보지는 않았지만, 검 사어의 음운환경과 길이에 따라 비음치의 변이성이 달라질 수 있 음을 제안하고 있어 이에 대한 보다 체계적인 연구가 필요하다.

따라서 본 연구에서는 일반 성인과 아동 간에 검사어의 모음환 경과 길이에 따라 비음치의 검사-재검사 변이성이 달라지는지 살펴 봄으로써, 어떠한 검사어 조건이 상대적으로 일관성 있는 비음치 를 제시하는지 살펴보고자 한다.

\section{연구방법}

\section{연구대상}

본 연구에는 성인 20 명(남: 10 명, 여: 10 명)과 아동 4,5 세 각각 15 명(총 30명, 남: 16 명, 여: 14 명)이 참여하였다. 자료수집 당시 성인과 아동의 평균 연령은 각각 $21.7(\mathrm{SD}=1.42)$ 세와 $4.5(.51)$ 세였으며, 비 강 공명에 영향을 미칠 수 있는 비염, 부비동염 등이 없었다. 연구자 가 청지각적으로 판단하였을 때 공명, 음성, 청각, 조음상에 문제가 
없는 성인과 아동만을 연구에 포함하였다. 특히 아동의 경우 검사 어의 오조음이 평균 비음치와 비음치의 변이성에 영향을 끼칠 가 능성을 통제하기 위해 자료수집 전에 검사어를 충분히 연습하였으 며, 비음치 측정 과정에서 말소리의 오류를 보였던 아동의 비음치는 최종분석 자료에서 제외하였다

\section{검사어}

검사어는 구강 자음으로만 구성하였으며, 저모음 /아/와 고모음 /이/ 환경과 저모음과 고모음, 중모음이 비슷한 비율로 사용된 혼합 모음 환경으로 나누어 세 모음환경에서 $4,8,16,31$ 음절의 검사어 를 구성하였다. /아/모음 환경의 검사어는 Kim 등(2000) 연구에서 사용된 것이며, 이를 바탕으로 아동 수준에 알맞은 비교적 쉬운 어 휘를 선택하여 /이/모음 환경과 혼합모음 환경 문장을 개발하였다. 8 음절 이상의 저모음과 고모음 환경의 검사어에서는 검사어의 조 건을 지키면서 의미 있는 문장을 만드는 과정에서 중모음과 이중 모음이 비슷한 비율로 불가피하게 일부 포함되었다. 본 연구에서 사용한 검사어는 Appendix 1에 제시하였다.

\section{자료 수집 및 분석}

비음측정기는 Nasometer II Model 6450을 사용하였으며, 측정 의 결과값은 각 검사어의 평균 비음치 값을 사용하였다. 비음측정 기는 사용 지침서에 따라 벽이나 다른 물체로부터 본체를 $90 \mathrm{~cm}$ 이 상 떨어뜨려서 설치한 후, 매뉴얼에서 제시하는 0.9-1.1 사이의 수치 에 오도록 영점조절(calibration)을 하였다. 헤드기어의 분리판(separation plate)은 대상자의 코와 윗입술 사이의 중앙에 위치시켰으 며 말을 하는데 입술의 움직임을 방해하지 않도록 조절하였고, 분 리판이 피부에 닿는 것에 불편함을 보이는 대상자의 경우 투명관 을 사용하여 진행하였다. 분리판의 각도는 최대한 $90^{\circ}$ 로 유지하고 $\pm 15^{\circ}$ 의 각도를 벗어나지 않도록 하였다. 비음치 측정 전 헤드기어 착용과 비음측정기에 대한 충분한 설명과 시연을 통해 자료수집 과정에 익숙해지도록 하였고, 녹음 전 검사어를 읽고 연습할 수 있 는 시간을 가졌다. 설명 시간, 연습 시간 등을 포함하여 대상자 수 행 능력에 따라 총 검사시간은 25-30분 정도 소요되었다.

모든 자료는 제 2 저자가 따라말하기를 통해 수집하였다. 성인과 아동 모두에게 동일한 목소리 크기, 음도, 속도로 검사어를 일관성 있게 제시하였다. 검사자는 평소 대화 수준보다 조금 큰 60-70 dB 정도의 크기로 최대한 동일한 목소리와 속도로 검사어를 제시하였 다. 4 음절은 쉼 없이 한 호흡에 제시하였으나, 8 음절 이상의 검사어 는 쉼 없이 따라말하는 것이 어려워 8 음절은 2 번, 16 음절은 4 번, 31 음절은 7번씩 검사어를 나누어 제시하였다. 각 검사어의 끊어 말한
위치와 빈도는 Appendix 1에 표기하였다. 검사어를 끊어서 따라 말하는 것이 비음치에 영향을 끼치는지 성인을 대상으로 예비 실 험을 한 결과, 끊어 말할 때와 끊어 말하지 않을 때의 비음치는 유 의한 차이가 없음을 확인하였다. 모든 검사어를 1 차적으로 녹음한 뒤에 헤드기어를 그대로 착용한 채로 동일한 방법으로 바로 2 차 녹 음을 실시하여 비음치를 측정하였다.

자료수집이 끝난 후에 비음치의 검사-재검사 변이성을 살펴보기 위해 동일한 검사어에서 수집된 두 비음치를 서로 빼서 절대값을 구해 통계분석을 실시하였다. 또한 대상자들이 1 차와 2 차 비음치 측정에서 어느 정도의 차이를 보이는지 보다 자세하게 살펴보기 위 해서 각 검사어 별로 차이점수의 누적표를 만들어 성인과 아동 집 단 별로 각 차이점수를 보이는 대상자의 비율을 살펴보았다(Watterson \& Lewis, 2006).

\section{통계분석}

통계처리는 통계 프로그램 SPSS (statistics package for the social science, version 22.0)를 이용하였다. 성인과 아동 집단간 모음환경 과 검사어 길이에 따라 비음치의 차이점수가 달라지는지 살펴보기 위해 1피험자 간(성인 vs. 아동) - 2피험자 내(검사어의 모음환경과 길이) 혼합분산분석(mixed ANOVA)을 실시하였다. 사후 분석은 Bonferroni test을 통해 실시하였다. 분산의 동질성과 구형성 검정 을 위해 Box's test와 Mauchly's test를 실시하였으며 구형성 검정에 서 유의확률이 .05 이하일 경우 Epsilon 값을 확인하여 .75 이상이 면 개체 내 효과 검정 테이블 에서 Huynh-Feldt의 수정된 자유도와 값을 사용하고 .75 이상일 경우에는 Greenhouse-Geisser의 수정된 자유도와 값을 사용하였다. 모든 유의 수준은.05로 설정하였다.

\section{연구결과}

\section{비음치}

검사어의 모음환경과 길이에 따라 성인과 아동 집단 간 비음치의 변이성을 살펴보기 위해 두 번에 걸쳐 각 검사어에서 수집된 비음 치에 대한 기술통계값은 Table 1에 제시하였다. 첫 번째로 수집된 비음치 자료는 Shin과 $\mathrm{Ha}$ (2016)의 연구에서 발표된 자료와 일부 동일하다.

모음환경에 따른 비음치에 대한 선행연구와 일관성있게 고모음 환경에서 비음치가 가장 높게 나타났으며, 그 다음으로 혼합모음이 높고, 저모음 환경이 가장 낮은 비음치를 보였다(Ha \& Cho, 2015; Kim et al., 2000; Lewis, Watterson, \& Quint, 2000; Shin \& Ha, 2016). 
Table 1. Nasalance scores for each stimulus at the first and second recordings

\begin{tabular}{|c|c|c|c|c|c|c|c|}
\hline \multirow{3}{*}{ Number of syllables } & \multirow{3}{*}{ Group } & \multicolumn{6}{|c|}{ Vowel contexts } \\
\hline & & \multicolumn{3}{|c|}{ First recording } & \multicolumn{3}{|c|}{ Second recording } \\
\hline & & Low & High & Mixed & Low & High & Mixed \\
\hline \multirow[t]{2}{*}{4} & Children & 13.30 (3.82) & $23.60(5.85)$ & $19.10(5.61)$ & $13.60(3.72)$ & 23.07 (5.85) & $18.67(4.45)$ \\
\hline & Adults & $11.25(6.21)$ & $26.90(9.21)$ & $18.80(9.20)$ & $12.30(6.11)$ & 28.20 (12.30) & $18.80(9.04)$ \\
\hline \multirow[t]{2}{*}{8} & Children & $11.57(4.00)$ & 24.07 (7.49) & $16.70(4.10)$ & 11.33 (3.94) & $23.73(6.08)$ & 16.50 (4.61) \\
\hline & Adults & $16.00(7.03)$ & 26.30 (10.61) & 17.45 (6.94) & $16.15(7.60)$ & $26.85(10.21)$ & $17.30(7.56)$ \\
\hline \multirow[t]{2}{*}{16} & Children & $12.30(4.17)$ & 23.33 (6.71) & $16.27(4.38)$ & $11.73(4.27)$ & $24.33(6.10)$ & $16.13(4.45)$ \\
\hline & Adults & $12.35(6.00)$ & $25.25(9.54)$ & $17.35(6.25)$ & $13.10(7.04)$ & $25.90(9.80)$ & $17.50(7.04)$ \\
\hline \multirow[t]{2}{*}{31} & Children & $12.47(4.02)$ & 23.33 (6.12) & $17.43(4.62)$ & 12.67 (3.92) & $24.47(6.33)$ & $17.77(4.58)$ \\
\hline & Adults & $13.70(6.30)$ & $26.10(10.35)$ & $16.45(6.54)$ & $13.25(7.03)$ & $26.90(9.80)$ & $15.60(6.86)$ \\
\hline
\end{tabular}

Values are presented as mean (SD).

Table 2. Absolute difference in nasalance scores for each stimulus

\begin{tabular}{llccc}
\hline \multirow{2}{*}{$\begin{array}{c}\text { Number of } \\
\text { syllables }\end{array}$} & Group & \multicolumn{3}{c}{ Vowel contexts } \\
\cline { 3 - 5 } & & Low & High & Mixed \\
\hline 4 & Children & $1.97(1.27)$ & $3.60(3.23)$ & $2.27(2.08)$ \\
& Adults & $1.95(1.76)$ & $4.90(4.59)$ & $2.70(1.69)$ \\
8 & Children & $1.93(1.80)$ & $2.93(2.45)$ & $1.87(1.63)$ \\
& Adults & $1.95(1.85)$ & $2.95(2.21)$ & $1.55(1.39)$ \\
16 & Children & $1.63(1.40)$ & $2.73(2.36)$ & $1.73(1.41)$ \\
& Adults & $1.95(1.79)$ & $2.05(1.79)$ & $2.05(1.70)$ \\
31 & Children & $1.33(1.27)$ & $2.07(2.18)$ & $1.40(1.07)$ \\
& Adults & $1.65(1.42)$ & $2.30(1.98)$ & $1.45(1.57)$ \\
\hline
\end{tabular}

Values are presented as mean (SD).

\section{비음치 차이점수}

두 집단 간 동일한 검사어에서 헤드기어 변경 없이 연속적으로 두 번에 걸쳐 수집된 비음치를 서로 빼서 구한 차이점수의 절대값 에 대한 기술통계값은 Table 2와 같다. 저모음 환경에서는 성인과 아동 모두 평균 1 점대의 차이점수를 보였으며, 혼합모음 환경에서 는 1-2점의 차이점수를 보였다. 고모음 환경의 검사어에서는 평균 2-4점대로 상대적으로 큰 차이점수를 보였다. 검사어의 길이는 대 체적으로 4 음절 검사어에서 차이점수가 큰 경향을 보였는데, 아동 과 성인의 경우 4 음절 고모음 환경에서 각각 평균 3.6점과 4.9점의 차이점수를 보여 검사어 중에서 가장 큰 비음치 편차를 보였다.

두 집단 간 검사어의 모음환경과 길이에 따라 비음치 차이점수가 유의하게 달라지는지 혼합분산분석을 실시하기에 앞서 구형성 검 정을 실시한 결과, 모음과 길이, 모음과 길이간 상호작용에서 유의 확률이 .05 이하로 나타났고 Epsilon값이 .75 이상으로 나타나 HuynhFeldt의 수정된 자유도와 값을 사용하였다. 혼합분산분석 결과, 아 동과 성인 두 집단 간에는 비음치 차이점수가 유의미하게 다르지 않았다 $\left(F_{(1,48)}=.772, p=.384, \eta_{\mathrm{p}}{ }^{2}=.016\right)$. 반면에 검사어의 모음환경
$\left(F_{(1.722,82.652)}=16.716, p<.001, \eta_{\mathrm{p}}{ }^{2}=.258\right)$ 과 길이 $\left(F_{(2.795,134.167)}=9.479\right.$, $\left.p<.001, \eta_{\mathrm{p}}{ }^{2}=.165\right)$ 에 대해서는 유의하게 다른 비음치 차이점수를 보였다. 모든 변인 간 상호작용은 통계적으로 유의미하지 않았다. 검사어의 모음환경과 길이에 대한 Bonferroni 사후 검정을 실시한 결과, 고모음 환경의 검사어는 저모음과 혼합모음 환경의 검사어보 다 유의미하게 큰 비음치 차이점수를 보였다 $(p<.001)$. 저모음과 혼 합모음 환경에서의 비음치 차이점수는 유의미하게 다르지 않았다. 검사어의 길이에 대해서는 4 음절 검사어는 16 음절과 31 음절 검사 어보다 유의미하게 큰 비음치 차이점수를 보였다 $(p<.01)$.

\section{비음치 차이점수 누적표}

비음치 차이점수의 누적표를 작성하여 각 집단 내의 대상자들이 각 검사어에서 어느 정도로 검사-재검사차이를 보이는지 살펴보았 다. 성인과 아동의 자료를 각각 Table 3 과 Table 4 에 정리하였다. Tables 3과 4에서 "”" 왼쪽에 기재된 값은 각 차이점수를 보이는 대상자 의 수 또는 누적빈도를 나타내며 “” 오른쪽에 기재된 값은 대상자 의 수 또는 누적빈도가 각 집단에서 차지하는 비율을 의미한다. 예 를 들어 Table 3에서 저모음 환경의 4 음절 검사어를 산출하는 동안 측정한 1 차와 2 차 비음치 점수가 완전히 동일한, 즉 비음치 차이점수 가 0 인 성인이 2 명이었으며 이는 성인 집단에서 $10 \%$ 를 차지한다.

일반적으로 선행연구에서는 헤드기어를 재착용하지 않은 상태 에서는 3점 이내의 차이점수를, 헤드기어를 재착용한 경우에는 5 점 이내의 차이점수를 정상적인 비음치 편차로 간주한다(Litzaw \& Dalston, 1992; Seaver et al., 1991; Watterson \& Lewis, 2006; Van Doorn \& Purcell, 1998). 따라서 3점과 5점 이내의 차이점수를 보이 는 집단 내 대상자의 비율을 살펴보면, 먼저 성인의 경우 저모음 환 경의 $4,8,16,31$ 음절에서는 각각 $75 \%, 80 \%, 85 \%, 85 \%$ 가 3 점 이내의 차이점수를 보였다. 혼합모음 환경의 $4,8,16,31$ 음절에서는 각각 
Table 3. Cumulative frequencies (raw/percentage) of absolute differences in nasalance scores for each stimulus of adults

\begin{tabular}{|c|c|c|c|c|c|c|c|c|c|c|c|c|}
\hline \multirow{3}{*}{$\begin{array}{l}\text { Nasalance score } \\
\text { difference }\end{array}$} & \multicolumn{12}{|c|}{ Vowel contexts } \\
\hline & \multicolumn{4}{|c|}{ Low } & \multicolumn{4}{|c|}{ High } & \multicolumn{4}{|c|}{ Mixed } \\
\hline & $4^{\mathrm{a}}$ & 8 & 16 & 31 & 4 & 8 & 16 & 31 & 4 & 8 & 16 & 31 \\
\hline 0 & $2 / 10$ & $6 / 30$ & $4 / 20$ & $4 / 20$ & $2 / 10$ & $0 / 0$ & $4 / 20$ & $0 / 0$ & $1 / 5$ & $5 / 25$ & $4 / 20$ & $4 / 20$ \\
\hline$\leq 1$ & $13 / 65$ & $10 / 50$ & $10 / 50$ & $11 / 55$ & $5 / 25$ & $6 / 30$ & $11 / 55$ & $10 / 50$ & $6 / 30$ & $11 / 55$ & $8 / 40$ & $14 / 70$ \\
\hline$\leq 2$ & $15 / 75$ & $12 / 60$ & $14 / 70$ & $16 / 80$ & $7 / 35$ & $10 / 50$ & $12 / 60$ & $13 / 65$ & $11 / 55$ & $16 / 80$ & $14 / 70$ & $17 / 85$ \\
\hline$\leq 3$ & $15 / 75$ & $16 / 80$ & $17 / 85$ & $17 / 85$ & $9 / 45$ & $14 / 70$ & $15 / 75$ & $18 / 90$ & $12 / 60$ & $18 / 90$ & $16 / 80$ & $19 / 95$ \\
\hline$\leq 4$ & $16 / 80$ & $18 / 90$ & 18/90 & 19/95 & $12 / 60$ & $17 / 85$ & $17 / 85$ & 18/90 & $16 / 80$ & $19 / 95$ & 18/90 & 19/95 \\
\hline$\leq 5$ & $20 / 100$ & 19/95 & $18 / 90$ & $20 / 100$ & $13 / 65$ & 18/90 & $20 / 100$ & 18/90 & $18 / 90$ & $20 / 100$ & 19/95 & 19/95 \\
\hline$\leq 6$ & & $20 / 100$ & $20 / 100$ & & $16 / 80$ & $19 / 95$ & & $18 / 90$ & $20 / 100$ & & $20 / 100$ & 19/95 \\
\hline$\leq 7$ & & & & & $16 / 80$ & $19 / 95$ & & $19 / 95$ & & & & $20 / 100$ \\
\hline$\leq 8$ & & & & & 16/80 & $19 / 95$ & & $20 / 100$ & & & & \\
\hline$\leq 9$ & & & & & $17 / 85$ & 19/95 & & & & & & \\
\hline$\leq 10$ & & & & & $17 / 85$ & $20 / 100$ & & & & & & \\
\hline$\leq 11$ & & & & & $18 / 90$ & & & & & & & \\
\hline$\leq 12$ & & & & & $19 / 95$ & & & & & & & \\
\hline$\ldots$ & $\ldots$ & $\ldots$ & $\ldots$ & $\ldots$ & $\ldots$ & $\ldots$ & $\ldots$ & $\ldots$ & $\ldots$ & $\ldots$ & $\ldots$ & $\ldots$ \\
\hline$\leq 18$ & & & & & 20/100 & & & & & & & \\
\hline
\end{tabular}

anumber of syllables.

Table 4. Cumulative frequencies (raw/percentage) of absolute differences in nasalance scores for each stimulus of children

\begin{tabular}{|c|c|c|c|c|c|c|c|c|c|c|c|c|}
\hline \multirow{3}{*}{$\begin{array}{l}\text { Nasalance score } \\
\text { difference }\end{array}$} & \multicolumn{12}{|c|}{ Vowel contexts } \\
\hline & \multicolumn{4}{|c|}{ Low } & \multicolumn{4}{|c|}{ High } & \multicolumn{4}{|c|}{ Mixed } \\
\hline & $4^{a}$ & 8 & 16 & 31 & 4 & 8 & 16 & 31 & 4 & 8 & 16 & 31 \\
\hline 0 & $3 / 10$ & $6 / 20$ & $7 / 23$ & $7 / 23$ & $5 / 17$ & $2 / 7$ & $2 / 7$ & $5 / 17$ & $6 / 20$ & $6 / 20$ & $8 / 27$ & $5 / 17$ \\
\hline$\leq 1$ & $14 / 47$ & $15 / 50$ & $17 / 57$ & $22 / 73$ & $9 / 30$ & $11 / 37$ & $9 / 30$ & $15 / 50$ & $15 / 50$ & $14 / 47$ & $14 / 47$ & 18/60 \\
\hline$\leq 2$ & $18 / 60$ & $23 / 77$ & $21 / 70$ & $24 / 80$ & $15 / 50$ & $18 / 60$ & $18 / 60$ & $20 / 67$ & $19 / 63$ & $22 / 73$ & $20 / 67$ & $27 / 90$ \\
\hline$\leq 3$ & $26 / 87$ & $25 / 83$ & $27 / 90$ & 28/93 & $18 / 60$ & $20 / 67$ & $22 / 73$ & $27 / 90$ & $22 / 73$ & $26 / 87$ & $26 / 87$ & 29/97 \\
\hline$\leq 4$ & $30 / 100$ & $25 / 83$ & 29/97 & 29/97 & 19/63 & $24 / 80$ & $26 / 87$ & 28/93 & $24 / 80$ & $28 / 93$ & $30 / 100$ & 29/97 \\
\hline$\leq 5$ & & 28/93 & $30 / 100$ & $30 / 100$ & $22 / 73$ & $24 / 80$ & 28/93 & 28/93 & $27 / / 90$ & 29/97 & & $30 / 100$ \\
\hline$\leq 6$ & & $30 / 100$ & & & $25 / 83$ & $25 / 83$ & $28 / 93$ & 29/97 & $29 / 97$ & 29/97 & & \\
\hline$\leq 7$ & & & & & $26 / 87$ & $29 / 97$ & 29/97 & 29/97 & $30 / 100$ & $30 / 100$ & & \\
\hline$\leq 8$ & & & & & $27 / 90$ & 29/97 & 29/97 & 29/97 & & & & \\
\hline$\leq 9$ & & & & & 28/93 & $30 / 100$ & 29/97 & 29/97 & & & & \\
\hline$\leq 10$ & & & & & $29 / 96$ & & 29/97 & 29/97 & & & & \\
\hline$\leq 11$ & & & & & $29 / 97$ & & 29/97 & $30 / 100$ & & & & \\
\hline$\leq 12$ & & & & & $30 / 100$ & & $30 / 100$ & & & & & \\
\hline
\end{tabular}

${ }^{a}$ Number of syllables.

$60 \%, 90 \%, 80 \%, 95 \%$ 가, 고모음 환경의 4 가지 길이의 검사어에서는 각각 $45 \%, 70 \%, 75 \%, 90 \%$ 의 대상자들이 3 점 이내의 차이점수를 보 였다. 5 점 이내의 차이점수를 기준으로 살펴보면, 저모음 환경의 4 , $8,16,31$ 음절에서는 각각 $100 \%, 95 \%, 90 \%, 100 \%$ 로 거의 모든 성인 이 1 차와 2 차의 비음치 측정에서 5 점 이내의 차이를 보이는 것으로 나타났다. 혼합모음 환경의 $4,8,16,31$ 음절에서도 비슷하게 각각 $90 \%, 100 \%, 95 \%, 95 \%$ 로 $1-2$ 명을 제외한 거의 모든 성인이 5 점 이내
의 차이점수를 보였다. 고모음 환경의 $4,8,16,31$ 음절에서는 각각 $65 \%, 90 \%, 100 \%, 90 \%$ 의 성인들이 5 점 이내의 차이점수를 보였다. 특히 고모음 환경의 4 음절 검사어에서는 3 명이 10 점 이상의 비음 치 차이점수를 보였으며, 1 명은 동일한 검사어에서 연속적으로 측 정한 두 비음치의 차이가 18 점으로 상당히 큰 변이성을 보였다.

아동의 경우에도 성인과 비슷하게 다른 모음환경의 검사어에 비 해 고모음 환경의 검사어에서 5 점 이상의 비음치 차이점수를 보이 
는 대상자의 비율이 높았다. 저모음 환경의 $4,8,16,31$ 음절에서는 각각 $87 \%, 83 \%, 90 \%, 93 \%$ 의 아동들이 3 점 이내의 차이점수를 보였 다. 혼합모음 환경의 $4,8,16,31$ 음절에서는 각각 $73 \%, 87 \%, 87 \%$, $97 \%$ 가, 고모음 환경의 4 가지 검사어에서는 각각 $60 \%, 67 \%, 73 \%$, $90 \%$ 의 아동들이 3 점 이내의 차이점수를 보였다. 5 점 이내의 기준 으로 살펴보면, 저모음 환경의 $4,8,16,31$ 음절에서는 각각 $100 \%$, $93 \%, 100 \%, 100 \%$ 로 거의 모든 아동이 1 차와 2 차의 비음치 측정에 서 5 점 이내의 차이를 보였다. 혼합모음 환경의 $4,8,16,31$ 음절에서 도 각각 $90 \%, 97 \%, 100 \%, 100 \%$ 로 4,8 음절에서 $1-2$ 명을 제외하고는 모든 아동이 5 점 이내의 차이점수를 보였다. 고모음 환경의 $4,8,16$, 31 음절에서는 각각 $73 \%, 80 \%, 93 \%, 93 \%$ 의 아동들이 5 점 이내의 차 이점수를 보여 4-8음절의 짧은 검사어에서 5점 이상의 차이점수를 보이는 아동의 수가 상대적으로 많았다. 아동 중 2 명이 고모음 환경 의 $4,16,31$ 음절의 검사어에서 10 점 이상의 큰 차이점수를 보였다.

\section{논의 및 결론}

본 연구는 일반성인과아동을 대상으로 모음환경과 길이를 달리한 검사어 조건에서 연속해서 비음치를 두 번 측정하여 구한 비음치 차 이점수를 토대로 집단과 검사어의 모음환경과 길이에 따라 비음치의 검사-재검사 변이성이 어떠한지 살펴보고자 하였다. 연구결과 성인과 아동 모두 저모음 환경에서 차이점수가 평균 1 점대로 가장 작은 차이 를 보였으며, 그 다음으로 혼합모음, 고모음 환경의 검사어 순서로 차 이점수가 점차 증가하였다. 특히 고모음 환경의 4 음절 검사어에서 성 인은 두 비음치간의차이가 평균 4 점대로 가장 큰 편차를 보였다.

두 집단 간 검사어의 모음환경과 길이에 따라 비음치 차이점수가 유의하게 달라지는지 혼합분산분석을 실시한 결과, 먼저 아동과 성 인 두 집단 간에는 비음치 차이점수가 유의미하게 다르지 않았다. 이러한 결과는 연인두 폐쇄와 개방의 타이밍상의 불안정성을 토대 로 아동이 성인보다 더 변이적인 비음치를 보일거라고 제안한 $\operatorname{Van}$ Doorn과 Purcell (1998)의 추측과는 다르다. 비음치 차이점수 누적 표를 토대로 두 집단의 특성을 자세히 살펴보면, 성인과 아동 모두 $90 \%$ 이상의 대상자들이 저모음과 혼합모음 환경의 검사어에서 5 점 이내의 차이점수를 보였다. 또한 고모음 환경의 검사어에서는 비음치 차이점수가 증가해 5점 이내의 차이점수를 보이는 대상자 비율이 감소하기는 하였으나 성인과 아동은 비슷한 비율로 5 점 이 내의 차이점수를 보였다. 하지만 고모음 환경의 4 음절어에서 성인 한 명이 비음치 차이점수가 18점으로 상당히 큰 편차를 보였으며, 이 성인의 비음치 차이점수로 인해 성인 집단의 평균이 4.9 점으로 3.6점의 아동 평균과 비교해 상대적으로 큰 차이점수를 보였다. 이
와 비슷하게 Watterson 등(2005) 연구도 헤드기어를 다시 착용하 지 않고 측정한 두 번의 비음치에서 12 점의 차이를 보이는 성인 화 자가 있었다고 보고하였다. 이러한 결과는 검사-재검사 비음치 변 이성은 정상적인 말 산출능력을 보이는 아동과 성인 사이에서 발달 적인 차이를 보이기 보다는 말 산출의 음향음성적인 면에서 정상적 인 범위에서 개인 내 편차를 보이는 화자가 있음을 제안하고 있다.

검사어의 모음환경에 따라 유의하게 다른 비음치 차이점수를 보 였는데, 저모음과 혼합모음 환경의 검사어와 비교해 고모음으로만 구성된 검사어에서 비음치 차이점수가 유의미하게 증가해 상대적 으로 높은 검사-재검사 변이성을 보였다. 이러한 연구결과는 피어 슨 상관계수를 토대로 비음치의 검사-재검사 신뢰도를 살펴본 Kim 등(2000)의 보고와는 다소 차이가 있다. Kim 등(2000)의 연구에서 는 전설 고모음 /이/ 환경의 검사어가 상관계수가 .88 로 가장 높았 으며, 그 다음으로 후설 고모음 /우/ 환경의 검사어가 .79, 저모음 /아/ 환경이 .76으로 가장 낮았다. 이러한 상이한 결과는 연속적으 로 녹음 수집된 두 비음치의 차이점수를 토대로 통계분석을 실시 하고 차이 점수의 누적표를 작성해서 살펴본 본 연구와 분석 방법 상의 차이로 인한 것일 수 있다. 고모음 환경에서 비음치의 차이점 수가 상대적으로 높은 이유에 대해서는 / 이/모음의 조음 특성과 그 로 인한 공기역학적, 음향학적 특성을 바탕으로 추론해볼 수 있다. 고모음 / 이/는 다른 저모음에 비해 구강이 좁아지면서 구강 내 기류 에 대한 저항이 커져 상대적으로 비강 내 음향학적 에너지가 증가 하기 때문에(Gildersleeve-Neumann \& Dalston, 2001) 다른 모음에 비해 고모음 /이/의 평균 비음치가 높다(Awan, Omlar, \& Watts, 2011; Ha \& Cho, 2015; Kim et al., 2000; Lewis et al., 2000; Shin \& $\mathrm{Ha}, 2016)$. 고모음 /이/는 산출할 때 마다 구강 면적이 좁아지는 정 도와 기류의 저항 정도가 정상범위 내에서 미묘하게 달라지기 쉬워 구강과 비강 내 음향학적 에너지가 함께 편차를 보일 가능성이 다 른 모음에 비해 높을 수 있다. 따라서 고모음으로만 구성된 검사어 는 화자가 산출할 때 마다 비음치가 동일하지 않고 다른 수치가 나 올수 있다. 이러한 추론에 대해서는 고모음이 다른 모음에 비해 조 음 및 공기 역학적 변이성이 더 큰지에 대한 체계적인 연구를 통해 입증할 필요가 있겠다.

검사어의 길이에 대해서는 4 음절 검사어가 16 음절과 31 음절 검 사어보다 유의미하게 큰 비음치 차이점수를 보이는 것으로 나타났 다. 검사어가 짧을수록 검사-재검사 신뢰도가 낮아진다는 Kim 등 (2000)의 연구와도 일관성 있는 결과이다. 비음치는 전체 검사어를 산출하는 동안 지속적으로 변화하는 비강과 구강 내 음향학적 에 너지 비율의 평균을 의미한다. 따라서 검사어가 짧을수록 검사어 를 산출하는 동안 보이는 미묘한 조음 및 공기역학적 편차가 평균 
비음치에 보다 더 가중되고 민감하게 반영되어, 측정할 때 마다 비 음치가 달라지는 폭이 증가할 수 있다. 이러한 추론은 모음환경과 마찬가지로 구강 및 비강 내 조음 및 공기역학적 특성에 관한 연구 를 통해 입증할 필요가 있겠다.

비음치의 검사-재검사 변이성을 보고한 선행연구들은 공명 문제 가 없는 정상적인 말 산출을 하는 일반 화자를 대상으로 헤드기어 의 재착용 없이 화자 내 수행력의 변이성만을 고려했을 때는 3점 이 내로, 헤드기어를 재착용하고 다시 측정했을 때는 5점 이내의 차이 를 비음치의 일반적인 편차로서 간주하고 임상적으로 유의한 차이 는 아니라고 제안하였다(Litzaw \& Dalston, 1992; Seaver et al., 1991; Watterson \& Lewis, 2006; Van Doorn \& Purcell, 1998). 검사어의 길이가 비음치의 검사-재검사차이점수에 유의미한 영향을 끼친다 는 본 연구결과를 고려한다면, 선행연구와 본 연구를 비교하기 위 해서는 서로 비슷한 음운조건과 길이의 검사어를 사용한 연구 결 과를 참조해야 한다. 관련 선행연구는 주로 비자음이 없고 다양한 모음으로 구성된 83음절의 Zoo passage나 Zoo passage와 동일한 음운적 조건으로 어린 아동에게 사용하기 위해 개발된 29음절의 Turtle passage를 이용하였다. 본 연구에서 선행연구와 가장 비슷한 조건의 검사어는 혼합모음 환경의 31 음절 검사어이다. 해당 검사어 에서 3 점 이내의 차이점수를 보인 성인의 비율은 $95 \%$ 이고 아동은 $97 \%$ 로 선행연구의 제안처럼 대부분의 성인과 아동이 3 점 이내의 비음치 차이를 보이는 것으로 나타났다. 따라서 혼합모음 환경의 31 음절 검사어를 토대로 비음치를 측정할 경우에는 3 점 이내의 편차 는 공명상의 실질적인 변화로 해석할 수 없고 일반적인 측정의 편차 로 해석해야 한다. 하지만 해당 검사어에서 각각 7점과 5점의 차이 점수를 보이는 성인과 아동이 한 명씩 있었기 때문에 일부 화자는 뚜렷한 병리적인 이유 없이 3점 이상의 편차를 보일 수 있음을 고려 해야 한다. 궁극적으로 공명 문제나 수술 또는 언어치료로 인한 공 명상의 변화를 타당하고 정확하게 평가하기 위해서는 적어도 동일 한 검사어를 연속해서 두 번 이상 측정하여 구한 비음치의 평균값 을 사용하는 것이 필요하다. 고모음으로만 구성되고 검사어의 길이 가 4음절로 짧을 경우 측정 간 높은 비음치 편차를 보일 수 있으므 로, 제한된 검사어만을 사용해야 하는 경우 적어도 8 음절 이상의 저모음이나 혼합모음 환경의 검사어를 선택하는 것이 적절하다.

\section{REFERENCES}

Awan, S. N., Omlor, K., \& Watts, C. R. (2011). Effects of computer system and vowel loading on measures of nasalance. Journal of Speech, Language, and Hearing Research, 54, 1284-1294.
Chermak, G. D., \& Schneiderman, C. R. (1985). Speech timing variability of children and adults. Journal of Phonetics, 13, 477-480.

Cho, S. H., \& Ha, S. (2015). The relationship between nasality ratings and nasalance scores according to vowel context and speakers' sex: sensitivity and specificity. Communication Sciences \& Disorders, 20, 72-84.

Gildersleeve-Neumann, C. E., \& Dalston, R. M. (2001). Nasalance scores in noncleft individuals: why not zero? The Cleft Palate-Craniofacial Journal, $38,106-111$.

Ha, S., \& Cho, S. H. (2015). Nasalance scores for normal Korean-speaking adults and children: effects of age, vowel context, and stimulus length. International Journal of Pediatric Otorhinolaryngology, 79, 1235-1239.

Kent, R. D. (1992). The biology of phonological development. In C. A. Ferguson et al. (Eds.), Phonological development: models, research, implications (pp. 65-90). Timonium, MD: York Press

Kim, M., Sim, H. S., \& Choi, H. S. (2000). The effects of phonetic context and stimulus length on the nasalance score in normal adults. Korean Journal of Communication Disorders, 5, 91-105.

Kuehn, D. P., \& Moller, K. T. (2000). Speech and language issues in the cleft palate population: the state of the art. The Cleft Palate-Craniofacial Journal, $37,348-348$

Lewis, K. E., Watterson, T., \& Blanton, A. (2008). Comparison of short-term and long-term variability in nasalance scores. The Cleft Palate-Craniofacial Journal, 45, 495-500.

Lewis, K. E., Watterson, T., \& Quint, T. (2000). The effect of vowels on nasalance scores. The Cleft Palate-Craniofacial Journal, 37, 584-589.

Litzaw, L. L., \& Dalston, R. M. (1992). The effect of gender upon nasalance scores among normal adult speakers. Journal of Communication Disorders, $25,55-64$.

Seaver, E. J., Dalston, R. M., Leeper, H. A., \& Adams, L. E. (1991). A study of nasometric values for normal nasal resonance. Journal of Speech, Language, and Hearing Research, 34, 715-721.

Shin, I. S., \& Ha, S. (2016). Effects of vowel contexts, stimulus length, and age on nasalance. Phonetics and Speech Science, 8, 111-116.

Van Doorn, J., \& Purcell, A. (1998). Nasalance levels in the speech of normal Australian children. The Cleft Palate-Craniofacial Journal, 35, 287-292.

Watterson, T., \& Lewis, K. E. (2006). Test-retest nasalance score variability in hypernasal speakers. The Cleft Palate-Craniofacial Journal, 43, 415-419.

Watterson, T., Lewis, K., \& Brancamp, T. (2005). Comparison of nasalance scores obtained with the Nasometer 6200 and the Nasometer II 6400. The Cleft Palate-Craniofacial Journal, 42, 574-579. 
Appendix 1. 검사어

\begin{tabular}{|c|c|c|c|}
\hline \multirow{2}{*}{ 길이 } & \multicolumn{3}{|c|}{ 환경 } \\
\hline & /아/ & 101/ & 혼합 \\
\hline 4 & 바다 가자 & 이 집이야 & 집이 작아 \\
\hline 8 & 아가야/ 바다에 가자/ & 이 집이/ 돼지 집이야/ & 지이 차로/ 집에 가자/ \\
\hline 16 & 바다에서/ 자라와/ 가재와/ 소라 잡아보자/ & 이 지비/돼지 집이고/ 이집 이/ 토끼 집이야/ & 지이가/ 티 입고/ 바지 입고/ 바다 걸어 가자/ \\
\hline 31 & 가게에서/ 사과하고/ 과자 사자/ 바다에서/ & 이 집이/ 코끼리 집이고/ 이 집이/ 기러기 집이야/ & 지이가 티 입고/ 바지 입고/ 바다로 가자/ \\
\hline & 자라하고/ 가재 잡아서/ 아가에게 가자/ & 이리 와/ 여기 이 집이/ 오리 집이야/ & 고기 잡고/고기 하고/차타고/집으로 가자/ \\
\hline
\end{tabular}

‘' 끊어 읽는 단위. 


\section{국문초록}

\section{검사어 모음환경과 길이에 따른 성인과 아동의 비음치 변이성}

하승희 ${ }^{\prime} \cdot$ 신일산 ${ }^{2}$

1한림대학교 언어청각학부, 한림청각언어연구소, ${ }^{2}$ 한림대학교 보건과학대학원 언어병리학과

배경 및 목적: 일반 성인과 아동을 대상으로 검사어의 모음환경과 길이에 따라 비음치의 검사-재검사 결과가 달라지는지 살펴보았다. 방법: 성인 20명과 만 4-5세 아동 30명을 대상으로 고모음, 저모음, 혼합모음 환경에서 각각 $4,8,16,31$ 음절로 구성된 검사어를 사용하 였다. 따라말하기를 통해 각 검사어의 비음치를 두 번씩 측정하였다. 1 차와 2 차에 수집된 비음치의 차이점수를 토대로 집단 간 검사어 의 모음환경과 길이에 따라 비음치의 검사-재검사 결과가 달라지는지 살펴보았다. 결과: 검사어의 모음환경과 길이에 따라 비음치 차이 점수가 유의미하게 다르게 나타났고, 성인과 아동 집단 간에는 유의미한 차이가 없었다. 모든 변인간 상호작용 효과는 모두 유의미하지 않았다. 사후분석 결과, 고모음 환경의 검사어가 저모음과 혼합모음보다 유의미하게 큰 비음치 차이점수를 보였으며, 4 음절 검사어는 16,31 음절 검사어보다 유의미하게 큰 비음치 차이점수를 보였다. 고모음 환경의 4 음절에서 두 비음치 간의 차이점수가 5 점 이상으로 높 은 변이성을 보이는 성인과 아동의 수가 상대적으로 많았다. 논의 및 결론: 본 연구결과는 검사어의 모음환경과 길이에 따라 검사-재검 사 비음치 결과가 달라지고, 고모음이 많이 포함되고 검사어가 짧을수록 비음치 변이성이 높아짐을 제시하고 있다. 비음측정기 검사의 신뢰도와 타당도를 높이기 위해서는 동일한 검사어를 연속해서 두 번 이상 측정하여 개인 내 편차를 확인하는 것이 필요하다.

핵심어: 비음치, 모음환경, 검사어 길이, 성인, 아동

\section{참고문헌}

김민정, 심현섭, 최홍식(2000). 음운환경과 검사어 길이가 정상성인의 비음치에 미치는 영향. 언어청각장애연구, 5, 91-105.

신일산, 하승희(2016). 검사어의 모음환경과 길이 및 연령에 따른 비음치. 말소리와음성과학, 8, 111-116.

조성현, 하승희(2015). 모음환경과 화자의 성별에 따른 비성의 청지각적 평가와 비음치간의 상관관계: 민감도와 특이도를 중심으로. 언어청각장애연

구, 20,72-84. 